\title{
A Relative Superior Julia Set and Relative Superior Tricorn and Multicorns of Fractals
}

\author{
Priti Dimri \\ Head \\ Dept. of Computer Science and \\ Engineering \\ G.B.Pant Engineering College \\ Ghurdauri, Pauri
}

\author{
Shashank Lingwal \\ Dept. of Computer Science and \\ Engineering \\ G.B.Pant Engineering College \\ Ghurdauri, Pauri
}

\author{
Ashish Negi \\ Associate Professor \\ Dept. of Computer Science and \\ Engineering \\ G.B.Pant Engineering College \\ Ghurdauri, Pauri
}

\begin{abstract}
In this paper we investigate the new Julia set and a new Tricorn and Multicorns of fractals. The beautiful and useful fractal images are generated using Ishikawa iteration to study many of their properties. The paper mainly emphasizes on reviewing the detailed study and generation of Relative Superior Tricorn and Multicorns along with Relative Superior Julia Set.
\end{abstract}

\section{Keywords}

Complex dynamics, relative superior Julia set, Ishikawa iteration, Relative superior Tricorn, Relative superior Multicorns.

\section{INTRODUCTION}

The term 'Fractal' was coined by Benoit B Mandelbrot, in 1975 to denote his generalisation of complex shapes. Fractal is derived from Latin word 'fractus' which describes the appearance of broken stone : irregular and fragmented. The object Mandelbrot set, given by Mandelbrot 1979 and its relative object Julia set due to their beauty and complexity of their nature have become elite area of research nowadays. The fractal graphics are generally obtained by "colouring" the escape speed of the seed points within the certain regions of complex plane that give rise to the unbounded orbits.

Many authors have presented the papers on several "orbit traps" rendering methods to create the artistic fractal images. An orbit trap is a bounded area in complex plane into which an orbiting point may fall. Motivated by this idea of "orbit traps", Chauhan [4] introduces the different type of orbit traps for Ishikawa iteration procedure. They have considered Julia sets of $z_{n+1}=a z_{n}^{2}+c$, as orbit traps to explore their relevant fractal images, since, it is connected and bounded for a and $\mathrm{c}$.

Recently Shizuo [15] has quoted the Multicorns as the generalized Tricorns or the Tricorns of higher order and presented various properties of them. Tricorn are being used for commercial purpose, e.g. Tricorn Mugs and Tricorn $\mathrm{T}$ shirts. Multicorns are symmetrical objects. Their symmetry has been studied by Lau and Schleicher [11]. Negi [16] have introduced a new class of Relative Superior Multicorns using Ishikawa iterates and also studied their corresponding Relative Superior Julia sets.

\section{ELABORATION OF CONCEPT INVOLVED}

\subsection{Mandelbrot Set}

Definition 1. [17] The Mandelbrot set $M$ for the quadratic $Q_{C}(z)=\mathrm{z}^{2}+\mathrm{c}$ is defined as the collection of all $c \in C$ for which the orbit of point 0 is bounded, that is, $M=\left\{c \in C:\left\{Q_{c}^{n}(0)\right\} ; n=0,1,2,3 \ldots\right.$ is bounded $\}$

An equivalent formulation is

$M=\left\{c \in C:\left\{Q_{c}^{n}(0)\right.\right.$ does not tends to $\infty$ as $\left.\left.n \rightarrow \infty\right\}\right\}$

We choose the initial point 0 , as 0 is the only critical point of $\mathrm{Q}_{\mathrm{c}}$.

\subsection{Julia Set}

Definition 2. [17] The set of points $K$ whose orbits are bounded under the iteration function of $\mathrm{Q}_{\mathrm{c}}(\mathrm{z})$ is called the Julia set. We choose the initial point 0 , as 0 is the only critical point of $\mathrm{Q}_{\mathrm{c}}(\mathrm{z})$.

\subsection{Tricorn and Multicorns}

Please The study of connectedness locus for antiholomorphic polynomials $\bar{z}^{2}+c$ defined as Tricorn, coined by Milnor [14], plays intermediate role between quadratic and cubic polynomials.

Definition 3. [5] The Multicorns $\mathrm{A}_{\mathrm{c}}$, for the quadratic $A_{c}(z)=z^{\prime n}+c$ is defined as the collection of all $c \in C$ for which the orbit of the point 0 is bounded, that is, $A_{c}=\left\{c \in C: A_{c}(\mathrm{O})_{n=0,1,2,3 \ldots}\right.$ is bounded $\}$. An equivalent formulation $A_{c}=\left\{c \in C: A_{c}(0)\right.$ not tends to $\infty$ as $\left.n \rightarrow \infty\right\}$.

The Tricorn are special Multicorns when $\mathrm{n}=2$. As quoted by Devany [7][8], iteration of function $A_{c}=z^{1^{2}}+c$, using the Escape Time Algorithm, results in many strange and surprising structures. Devany [7][8] has named it Tricorns and observed that $f\left(z^{\prime}\right)$, the conjugate function of $f(z)$, is antipolynomial. Further, its second iterates is a polynomial of degree 4. The function $z^{\prime 2}+c$ is conjugate of $z^{\prime 2}+d$, where $d=e^{2 \pi i / 3}$, which shows that the Tricorn is symmetric under rotations through angle $2 \pi / 3$. The critical point for $\mathrm{A}_{\mathrm{c}}$ is 0 , since $c=A_{c}(\mathrm{O})$ has only one preimage whereas any other $w \in C$, has two preimages. 


\subsection{Picard's Orbit}

Definition 4. Let $X$ be a nonempty set and $f: X \rightarrow X$. For any point $x_{0} \in X$, the Picard's orbit is defined as the set of iterates of a point $x_{0}$, that is; $O(f, x)=\left\{x_{n} ; x_{n}=f\left(x_{n-1}\right), n=1,2,3 \ldots\right\}$.

In functional dynamics, we have existence of two different types of points. Points that leave the interval after a finite number are in stable set of infinity. Points that never leave the interval after any number of iterations have bounded orbits. So, an orbit is bounded if there exists a positive real number, such that the modulus of every point in the orbit is less than this number. The collection of points that are bounded, i.e. there exists $\mathrm{M}$, such that $\left|Q^{n}(z)\right| \leq M$, for all $\mathrm{n}$, is called as a prisoner set while the collection of points that are in the stable set of infinity is called the escape set. Hence the boundary of a prisoner set is simultaneously the boundary of escape set and that is Julia set for Q.

\subsection{Ishikawa Iteration}

Definition 5. Ishikawa Iterates [17]: Let $X$ be a subset of real or complex number and $f: X \rightarrow X$ for all $x_{0} \in X$, we have the sequence $\left\{x_{n}\right\}$ and $\left\{y_{n}\right\}$ in $X$ in the following manner:

$y_{n}=S^{\prime}{ }_{n} f\left(x_{n}\right)+\left(1-S_{n}^{\prime}\right) x_{n}$

$x_{n+1}=S_{n} f\left(y_{n}\right)+\left(1-S_{n}\right) x_{n}$

where $\mathrm{O} \leq S^{{ }^{\prime}}{ }_{n} \leq 1, \quad \mathrm{O} \leq S_{n} \leq 1$ and $S^{{ }^{\prime}}{ }_{n} \& S_{n}$ are both convergent to non-zero number.

\subsection{Relative Superior Mandelbrot Set}

Now we define Mandelbrot set for the function with respect to Ishikawa iterates. We call them as Relative Superior Mandelbrot sets.

Definition 6. [17] Relative Superior Mandelbrot set RSM for the function of the form $Q_{c}(z)=z^{n}+c$, where $\mathrm{n}=$ $1,2,3, \ldots$ is defined as the collection of $c \in C$ for which the orbit of 0 is bounded i.e. $R S M=\left\{c \in C: Q_{c}^{k}(0): k=0,1,2,3 \ldots\right\}$ is bounded.

In functional dynamics, we have existence of two different types of points. Points that leave the interval after a finite number are in stable set of infinity. Points that never leave the interval after any number of iterations have bounded orbits. So, an orbit is bounded if there exist a positive real number.

\subsection{Relative Superior Julia Set}

Definition 7. [17] The set of points RSK whose orbits are bounded under relative superior iteration of function $Q(z)$ is called Relative Superior Julia sets. Relative Superior Julia set of Q is boundary of Julia set RSK.

\section{GENERATING PROCESS}

The basic principle of generating fractals employs the iterative formula: $z_{n+1} \leftarrow f\left(z_{n}\right)$ where $\mathrm{z}_{0}=$ the initial valueof $\mathrm{z}$, and $z_{i}=$ the value of complex quantity $z$ at the $i^{\text {th }}$ iteration [17]. For example, the Mandelbrot's self-squared function for generating fractal is: $f(z)=z^{2}+c$, where $z$ and $c$ are both complex quantities. We propose the use of transformation function $z \rightarrow z^{n}+c, n \geq 2$ and $z \rightarrow\left(z^{n}+c\right)^{-1}$ for generating fractal images with respect to Ishikawa iterates, where $\mathrm{z}$ and $\mathrm{c}$ are the complex quantities and $\mathrm{n}$ is a real number. Each of these fractal images is constructed as twodimensional array of pixel. Each pixel is represented by a pair of $(\mathrm{x}, \mathrm{y})$ coordinates. The complex quantities $\mathrm{z}$ and $\mathrm{c}$ can be represented as:

$$
\begin{aligned}
& z=z_{x}+i z_{y} \\
& c=c_{x}+i c_{y}
\end{aligned}
$$

where $i=\sqrt{(-1)}$ and $\mathrm{z}_{\mathrm{x}}, \mathrm{c}_{\mathrm{x}}$ are the real parts and $\mathrm{z}_{\mathrm{y}}, \mathrm{c}_{\mathrm{y}}$ are the imaginary parts of $\mathrm{z}$ and $\mathrm{c}$ respectively. The pixel coordinates $(\mathrm{x}, \mathrm{y})$ may be associated with $\left(\mathrm{c}_{\mathrm{x}}, \mathrm{c}_{\mathrm{y}}\right)$ or $\left(\mathrm{z}_{\mathrm{x}}, \mathrm{z}_{\mathrm{y}}\right)$.

Based on this concept, the fractal images can be classified as follows:

(a) z-Plane fractals, wherein $(x, y)$ is a function of $\left(z_{x}, z_{y}\right)$.

(b) c-Plane fractals, wherein $(x, y)$ is a function of $\left(c_{x}, c_{y}\right)$.

In the literature, the fractals for $\mathrm{n}=2$ in $\mathrm{z}$ plane are termed as the Mandelbrot set while the fractals for $n=2$ in $c$ plane are known as Julia sets $[4,5]$

\section{ESCAPE CRITERIA FOR RELATIVE SUPERIOR MANDELBROT AND JULIA SET}

\subsection{Escape Criterion for Quadratics}

[13] Suppose that $|z|>\max \left\{|c|, 2 / s, 2 / s^{\prime}\right\}$, then $\left|z_{n}\right|>(1+\lambda)^{n}|z|$ and $|z| \rightarrow \infty$ as $n \rightarrow \infty$. So, $|z| \geq|c|$ and $|z|>2 / s$ as well as $|z|>2 / s^{\prime}$ shows the escape criteria for quadratics.

\subsection{Escape Criterion for Cubics}

[13] Suppose $|z|>\max \left\{|b|,(|a|+2 / s)^{1 / 2},\left(|a|+2 / s^{\prime}\right)^{1 / 2}\right\}$ then $\left|z_{n}\right| \rightarrow \infty$ as $n \rightarrow \infty$. This gives the escape criterion for cubic polynomials.

\subsection{General Escape Criterion}

[13] Consider $|z|>\max \left\{|c|,(2 / s)^{1 / 2},\left(2 / s^{\prime}\right)^{1 / 2}\right\}$ then $\left|z_{n}\right| \rightarrow \infty$ as $n \rightarrow \infty$ is the escape criterion

Note that the initial value $\mathrm{z}_{0}$ should be infinity, since infinity is the critical point of $z \rightarrow\left(z^{n}+c\right)^{-1}$. However, instead of starting with $\mathrm{z}_{0}=$ infinity, it is simpler to start with $\mathrm{z}_{1}=\mathrm{c}$, which yields the same result. A critical point of $z \rightarrow F(z)+c$ is a point where $F^{\prime}(z)=0$. 


\section{SIMULATION AND RESULTS}

Fixed point of quadratic polynomial- [4]

Table 1 : Orbit of $\mathrm{F}(\mathrm{Z})$ for $\left(\mathrm{z}_{0}=-1.71-0.24 \mathrm{i}\right)$

at $\mathrm{s}=0.3$ and s' $=0.4$

\begin{tabular}{|c|c|c|c|}
\hline $\begin{array}{c}\text { Number of } \\
\text { Iteration } \mathbf{i}\end{array}$ & $|\mathbf{F}(\mathbf{z})|$ & $\begin{array}{c}\text { Number of } \\
\text { Iteration } \mathbf{i}\end{array}$ & $|\mathbf{F}(\mathbf{z})|$ \\
\hline 1 & 1.7268 & 13 & 0.97304 \\
\hline 2 & 1.3866 & 14 & 0.97304 \\
\hline 3 & 1.2095 & 15 & 0.97304 \\
\hline 4 & 1.132 & 16 & 0.97304 \\
\hline 5 & 1.0602 & 17 & 0.97304 \\
\hline 6 & 1.0051 & 18 & 0.97304 \\
\hline 7 & 0.98257 & 19 & 0.97304 \\
\hline 8 & 0.97564 & 20 & 0.97304 \\
\hline 9 & 0.97308 & 21 & 0.97304 \\
\hline 10 & 0.9732 & 22 & 0.97304 \\
\hline 11 & 0.97308 & 23 & 0.97304 \\
\hline 12 & 0.97305 & 24 & 0.97304 \\
\hline
\end{tabular}

Fig. 1 : Observation : Here we observe that the value converges to a fixed point after 13 iterations

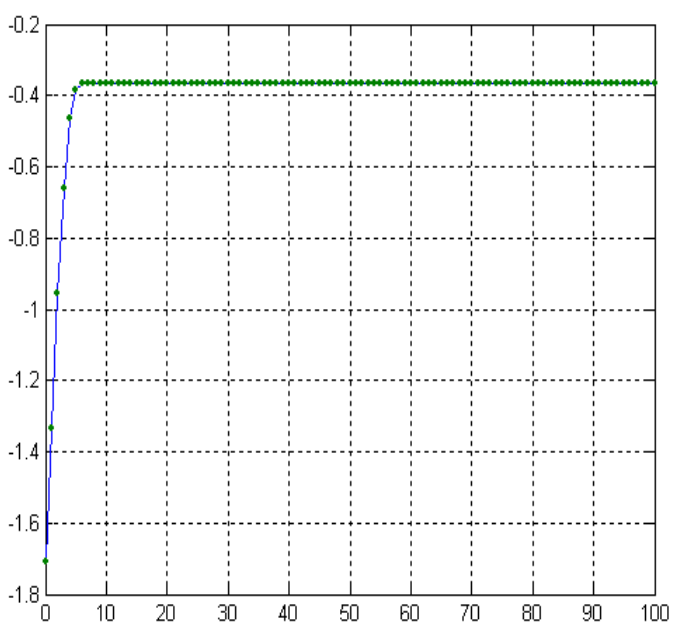

\section{Fixed Point for Cubic Polynomial}

Table 2 : Orbit of $\mathrm{F}(\mathrm{z})$ for $\left(\mathrm{z}_{0}=-0.08+0.057 \mathrm{i}\right)$ at $\mathrm{s}=0.8$ and $\mathrm{s}^{\prime}=0.2$

\begin{tabular}{|c|c|c|c|}
\hline $\begin{array}{c}\text { Number of } \\
\text { Iteration } \mathbf{i}\end{array}$ & $|\mathbf{F}(\mathbf{z})|$ & $\begin{array}{c}\text { Number of } \\
\text { Iteration } \mathbf{i}\end{array}$ & $|\mathbf{F}(\mathbf{z})|$ \\
\hline 10 & 0.26107 & 25 & 0.26713 \\
\hline 11 & 0.27154 & 26 & 0.26716 \\
\hline 12 & 0.26406 & 27 & 0.26721 \\
\hline 13 & 0.26942 & 28 & 0.26717 \\
\hline 14 & 0.26558 & 29 & 0.2672 \\
\hline
\end{tabular}

\begin{tabular}{|l|l|l|l|}
\hline 15 & 0.26833 & 30 & 0.26718 \\
\hline 16 & 0.26637 & 31 & 0.26719 \\
\hline 17 & 0.26777 & 32 & 0.26718 \\
\hline 18 & 0.26677 & 33 & 0.26719 \\
\hline 19 & 0.26749 & 34 & 0.26719 \\
\hline 20 & 0.26697 & 35 & 0.26719 \\
\hline 21 & 0.26734 & 36 & 0.26719 \\
\hline 22 & 0.26708 & 37 & 0.26719 \\
\hline 23 & 0.26717 & 38 & 0.26719 \\
\hline 24 & 0.26727 & 39 & 0.26719 \\
\hline
\end{tabular}

Fig. 2 : Observation : We skipped 09 iteration and value converges to a fixed point after 33 iterations

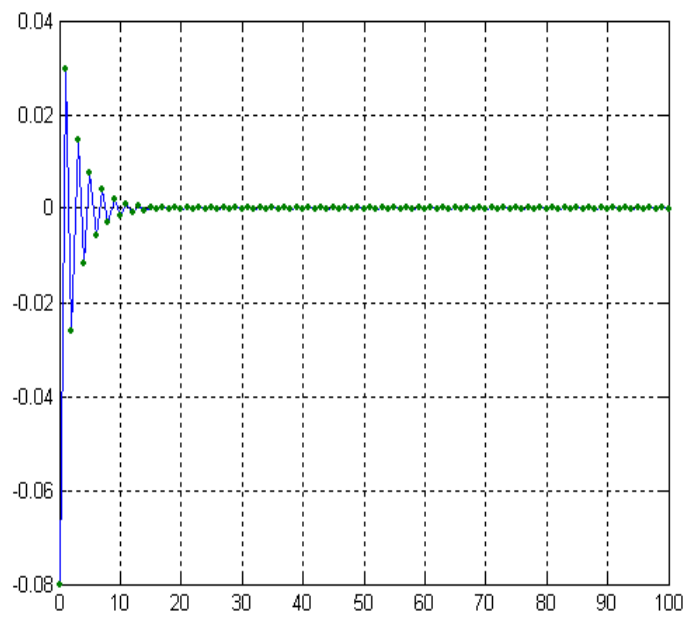

Fixed point for Bi-quadratic Polynomial

Table 3 : Orbit of $\mathrm{F}(\mathrm{z})$ for $\left(\mathrm{z}_{0}=0.134+0.128 \mathrm{i}\right)$ at $\mathrm{s}=0.3$ and $\mathrm{s}^{\prime}=0.4$

\begin{tabular}{|c|c|c|c|}
\hline $\begin{array}{c}\text { Number of } \\
\text { Iteration i }\end{array}$ & $|\mathbf{F}(\mathbf{z})|$ & $\begin{array}{c}\text { Number of } \\
\text { Iteration i }\end{array}$ & $|\mathbf{F}(\mathbf{z})|$ \\
\hline 81 & 0.9200 & 96 & 0.9199 \\
\hline 82 & 0.9196 & 97 & 0.9200 \\
\hline 83 & 0.9197 & 98 & 0.9200 \\
\hline 84 & 0.9201 & 99 & 0.9198 \\
\hline 85 & 0.9201 & 100 & 0.9198 \\
\hline 86 & 0.9198 & 101 & 0.9200 \\
\hline 87 & 0.9197 & 102 & 0.9200 \\
\hline 88 & 0.9200 & 103 & 0.9199 \\
\hline 89 & 0.9201 & 104 & 0.9198 \\
\hline 90 & 0.9199 & 105 & 0.9199 \\
\hline 91 & 0.9197 & 106 & 0.9200 \\
\hline
\end{tabular}




\begin{tabular}{|l|l|l|l|}
\hline 92 & 0.9199 & 107 & 0.9199 \\
\hline 93 & 0.9200 & 108 & 0.9199 \\
\hline 94 & 0.9199 & 109 & 0.9199 \\
\hline 95 & 0.9198 & 110 & 0.9199 \\
\hline
\end{tabular}

Fig. 3: Observation : We skipped 81 iteration and after 107 iteration value converges to a fixed point

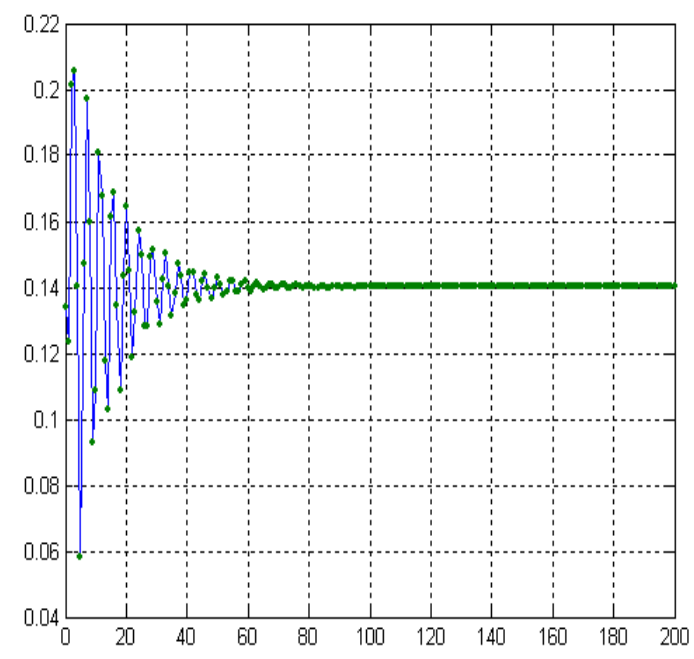

Generation of Relative Superior Julia Set

\section{Relative Superior Julia set for Quadratic}

Fig. 4 : Relative superior Julia set for $\mathrm{s}^{\prime}=1, \mathrm{~s}^{\prime}=0.3, \mathrm{c}=$ $0.430+0.18 \mathrm{i}$

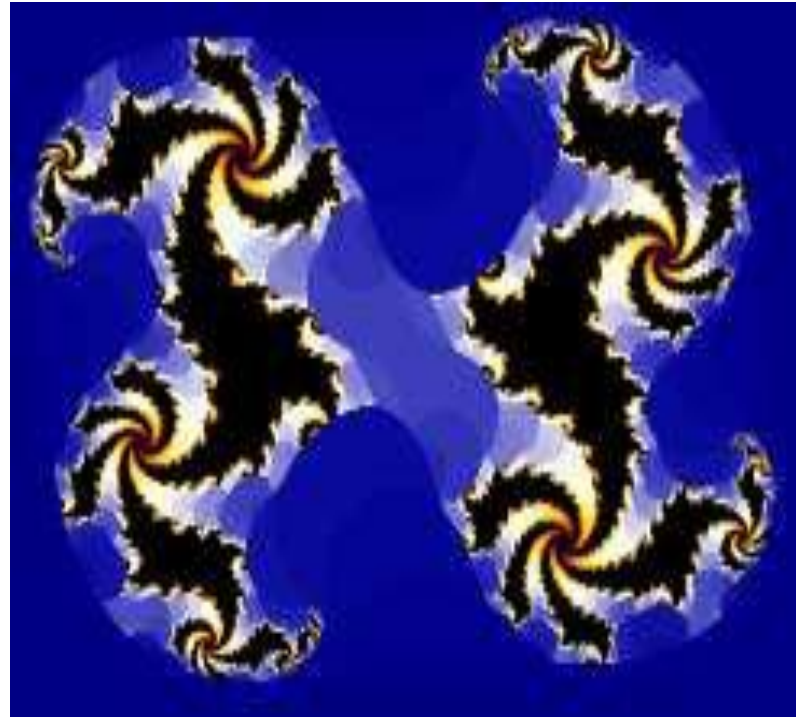

Fig. 5 : Relative Superior Julia Set for $\mathrm{s}=0.1, \mathrm{~s}=0.4, \mathrm{c}=-$ $20.26+0.097 \mathrm{i}$

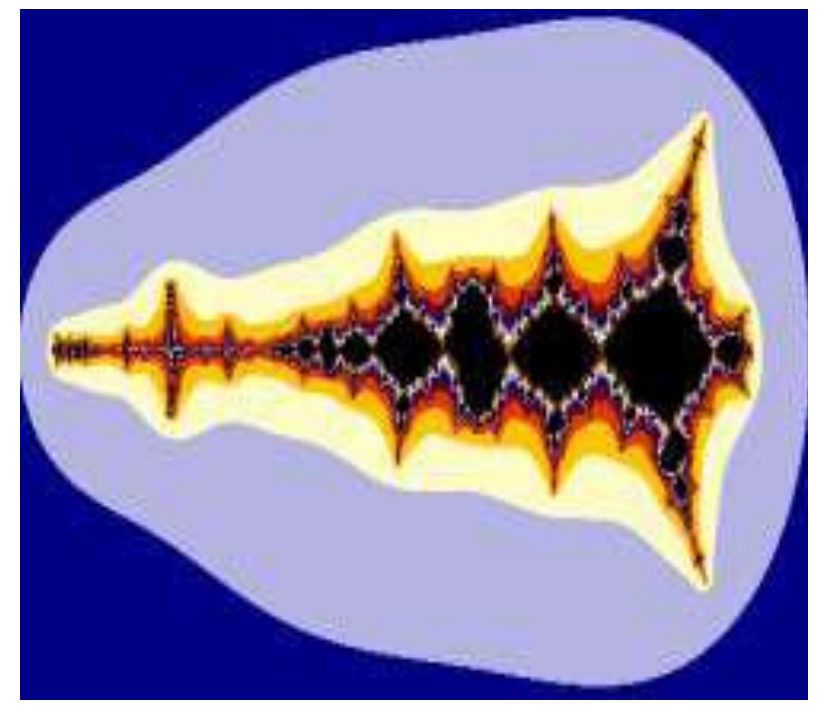

Relative Superior Julia set for Cubic function :

Fig. 6 : Relative Superior Julia set for $\mathrm{s}=1, \mathrm{~s}^{\prime}=0.5, \mathrm{c}=$ $0146+1.54 \mathrm{i}$

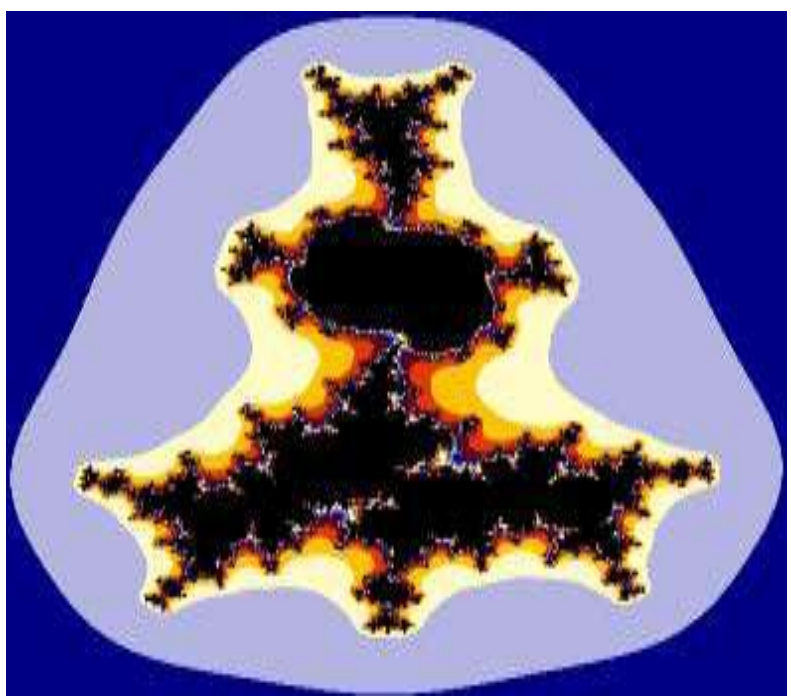

Fig. 7 : Relative Superior Julia Set for $\mathrm{s}=0.1, \mathrm{~s}=0.4, \mathrm{c}=-$ $1.6+6.7 \mathrm{i}$

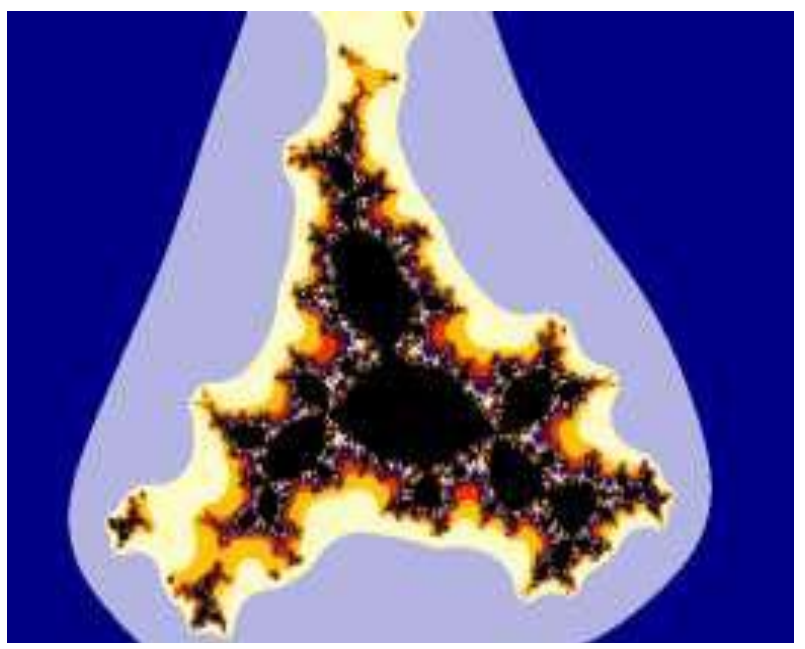

Relative Superior Julia Sets for Bi-Quadratic Function 
Fig. 8 : Relative Superior Julia set for $\mathrm{s}=1, \mathrm{~s}=0.5, \mathrm{c}=-1.57$

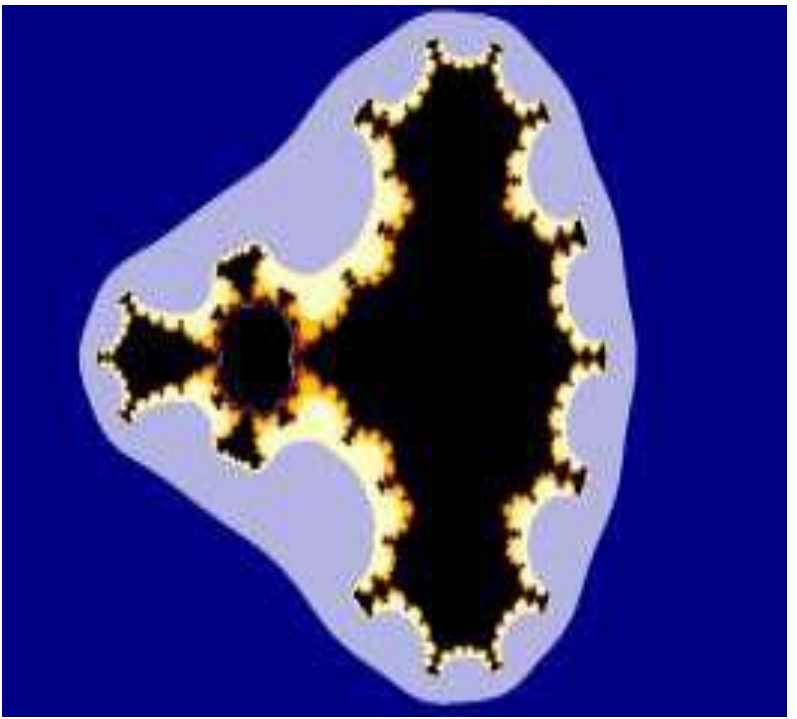

Fig. 9 : Relative Superior Julia Set for $\mathrm{s}=0.3, \mathrm{~s}=0.4, \mathrm{c}=-3.6$

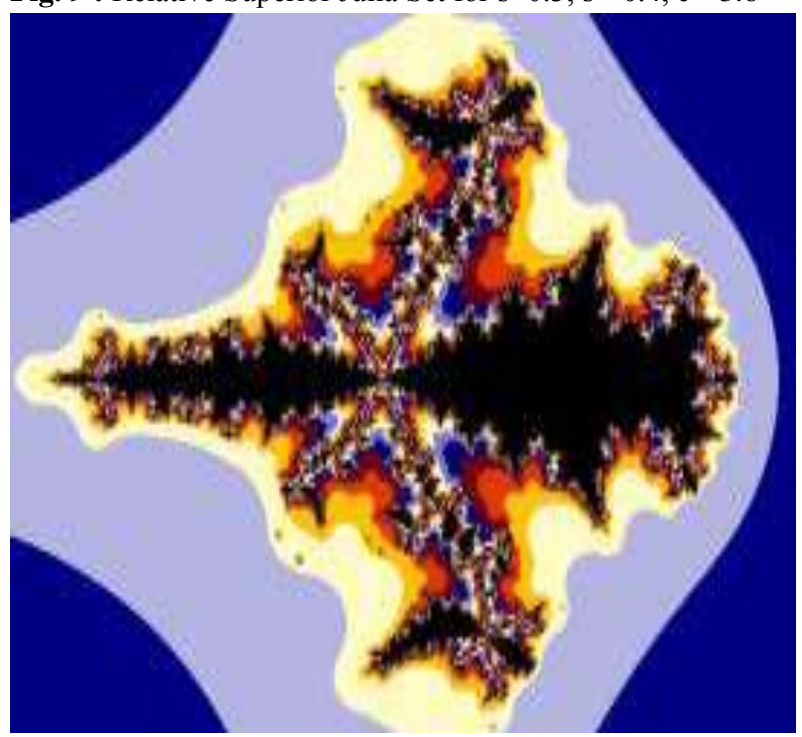

Fixed Points For Quadratic Polynomial - [5]

Table 4 : Orbit of $\mathrm{F}(\mathrm{z})$ for $\mathrm{s}=0.6, \mathrm{~s}^{\prime}=0.4$ at $\mathrm{z}_{0}=0.06415024553+0.03414122547 \mathrm{i}$

\begin{tabular}{|c|c|c|c|}
\hline $\begin{array}{c}\text { Number of } \\
\text { Iteration } \mathbf{i}\end{array}$ & $|\mathbf{F}(\mathbf{z})|$ & $\begin{array}{c}\text { Number of } \\
\text { Iteration } \mathbf{i}\end{array}$ & $|\mathbf{F}(\mathbf{z})|$ \\
\hline 1 & 0.07267 & 14 & 0.23604 \\
\hline 2 & 0.13743 & 15 & 0.23621 \\
\hline 3 & 0.17641 & 16 & 0.23638 \\
\hline 4 & 0.19914 & 17 & 0.23643 \\
\hline 5 & 0.21289 & 18 & 0.23646 \\
\hline 6 & 0.22143 & 19 & 0.23648 \\
\hline 7 & 0.22681 & 20 & 0.23649 \\
\hline 8 & 0.23025 & 21 & 0.2365 \\
\hline 9 & 0.23246 & 22 & 0.2365 \\
\hline
\end{tabular}

\begin{tabular}{|l|l|l|l|}
\hline 10 & 0.23389 & 23 & 0.23651 \\
\hline 11 & 0.23481 & 24 & 0.23651 \\
\hline 12 & 0.2354 & 25 & 0.23651 \\
\hline 13 & 0.23579 & 26 & 0.23651 \\
\hline
\end{tabular}

Fig. 10 : The Value Converges to a fixed point after 23 iterations

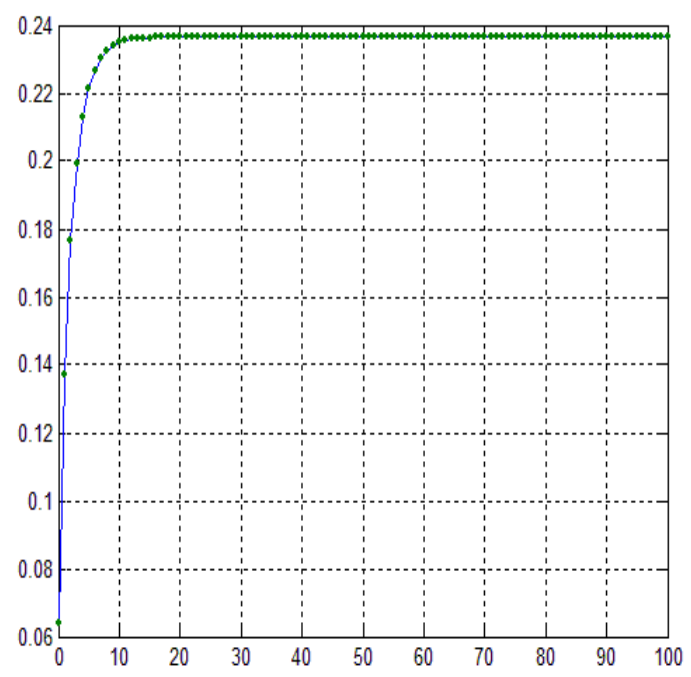

Fixed Point for Cubic Polynomial

Table 5 : Orbit of $\mathrm{F}(\mathrm{z})$ for $\mathrm{s}=0.5$, s' $=0.4$ at $\mathrm{z}_{0}=-$

$0.01341912254+0.001017666092 \mathrm{i}$

\begin{tabular}{|c|c|c|c|}
\hline $\begin{array}{c}\text { Number of } \\
\text { Iteration } \mathbf{i}\end{array}$ & $|\mathbf{F}(\mathbf{z})|$ & $\begin{array}{c}\text { Number of } \\
\text { Iteration } \mathbf{i}\end{array}$ & $|\mathbf{F}(\mathbf{z})|$ \\
\hline 1 & 0.013458 & 12 & 0.21207 \\
\hline 2 & 0.09368 & 13 & 0.2122 \\
\hline 3 & 0.14876 & 14 & 0.21228 \\
\hline 4 & 0.17784 & 15 & 0.21232 \\
\hline 5 & 0.19348 & 16 & 0.21235 \\
\hline 6 & 0.20199 & 17 & 0.21236 \\
\hline 7 & 0.20665 & 18 & 0.21236 \\
\hline 8 & 0.20922 & 19 & 0.21236 \\
\hline 9 & 0.21063 & 20 & 0.21237 \\
\hline 10 & 0.21141 & 21 & 0.21237 \\
\hline 11 & 0.21184 & 22 & 0.21237 \\
\hline
\end{tabular}


Fig. 11 : Here value converges to a fixed point after 20 iterations

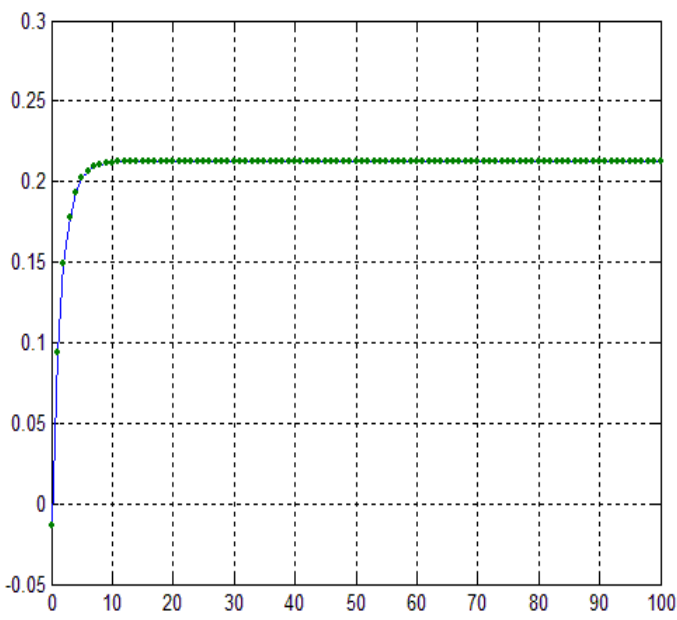

Fixed Points of Bi-Quadratic polynomial

Table 6 : Orbit of $\mathrm{F}(\mathrm{z})$ for $\mathrm{s}=0.8, \mathrm{~s}^{\prime}=0.2$ at $\mathrm{z}_{0}=$ $0.02786208647-0.03509673188 \mathrm{i}$

\begin{tabular}{|c|c|c|c|}
\hline $\begin{array}{c}\text { Number of } \\
\text { Iteration } \mathbf{i}\end{array}$ & $|\mathbf{F}(\mathbf{z})|$ & $\begin{array}{c}\text { Number of } \\
\text { Iteration } \mathbf{i}\end{array}$ & $|\mathbf{F}(\mathbf{z})|$ \\
\hline 1 & 0.044812 & 7 & 0.12663 \\
\hline 2 & 0.10592 & 8 & 0.12664 \\
\hline 3 & 0.12207 & 9 & 0.12664 \\
\hline 4 & 0.12563 & 10 & 0.12664 \\
\hline 5 & 0.12642 & 11 & 0.12664 \\
\hline 6 & 0.12659 & 12 & 0.12664 \\
\hline
\end{tabular}

Fig. 12 : Here the value converges to a fixed point after 8 iterations

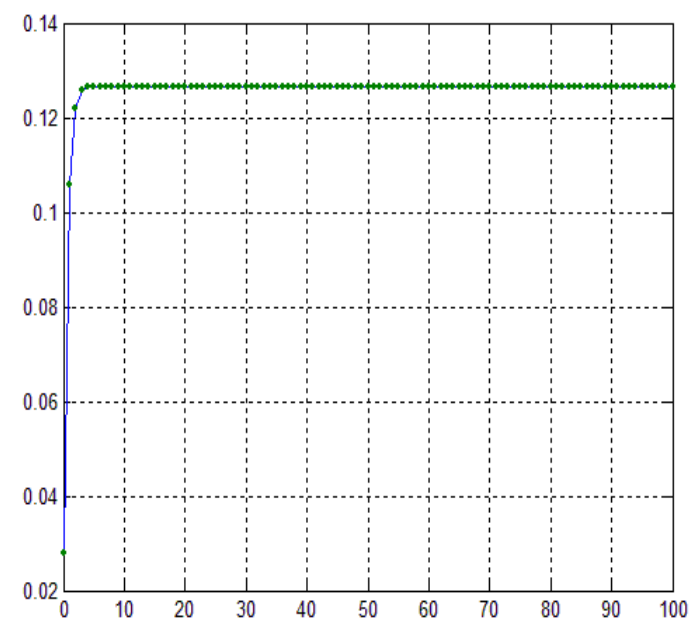

\section{Generation of Relative Superior Tricorns and Multicorns}

\section{Relative Superior Tricorn for Quadratic function}

Fig. 13 : Relative superior Tricorn for $\mathrm{s}^{\mathrm{s}} \mathrm{s}=1$

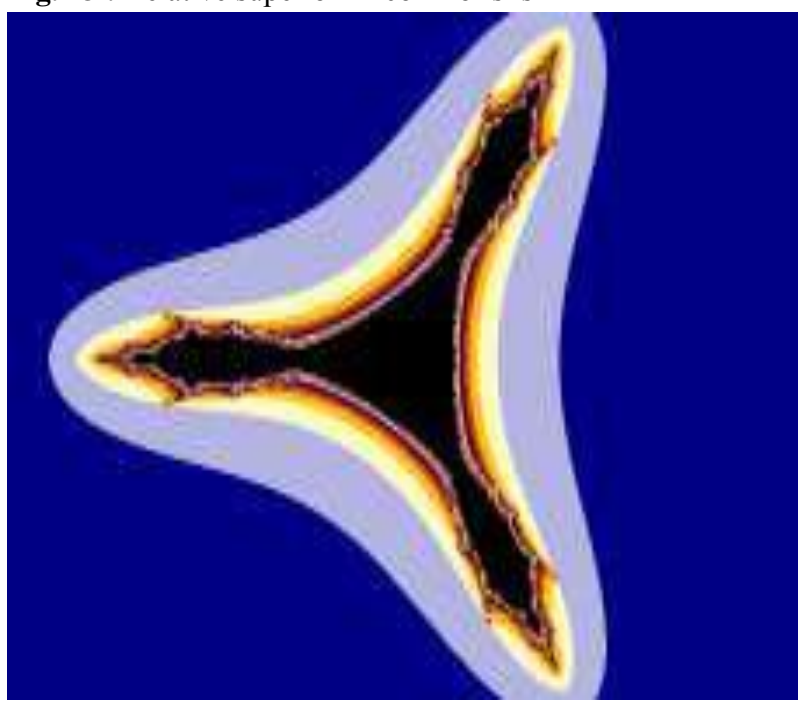

Fig. 14 : Relative Superior Tricorn for $\mathrm{s}=0.6, \mathrm{~s}^{\prime}=0.4$

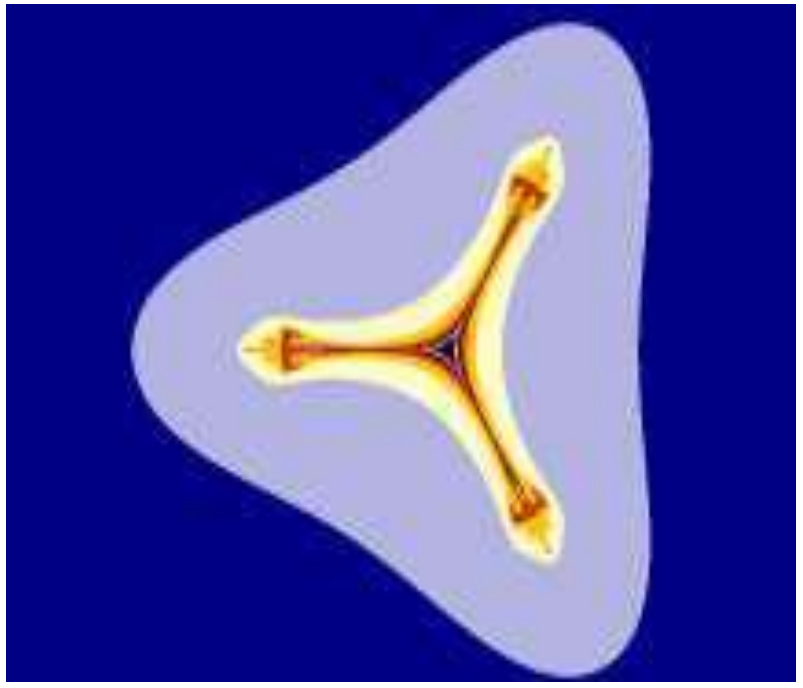

Relative Superior Multicorns for Cubic Function

Fig. 15 : Relative Superior Multicorns for $\mathrm{s}=1, \mathrm{~s}$ ' $=1$

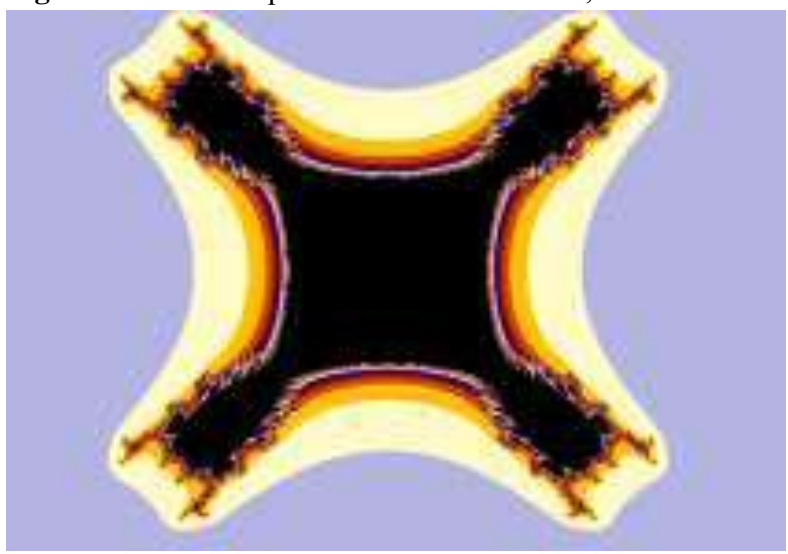


Fig. 16 : Relative Superior Multicorns for $\mathrm{s}=0.5, \mathrm{~s}=0.4$

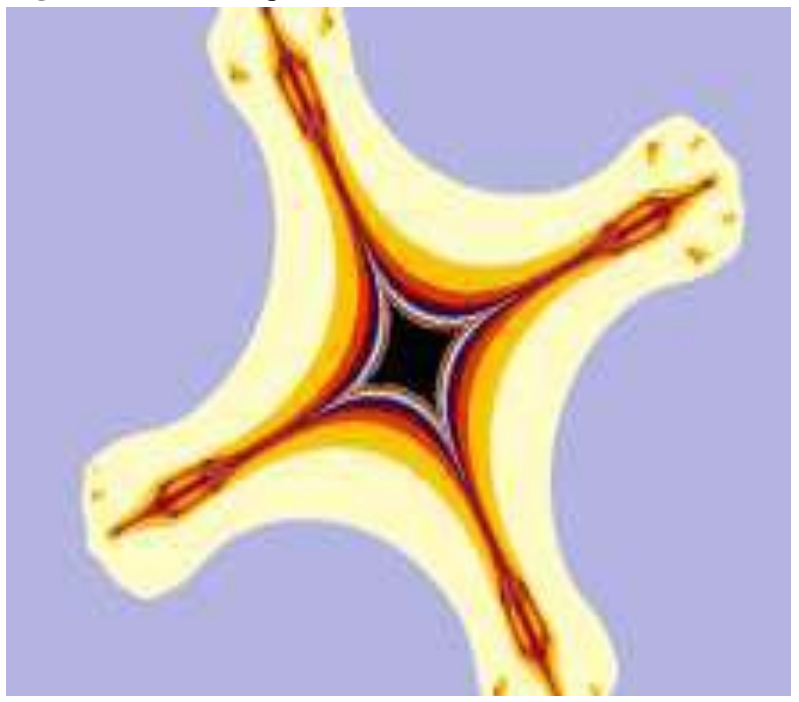

\section{Relative Superior Multicorns for Bi-quadratic function}

Fig. 17 : Relative Superior Multicorns for $s=s '=1$

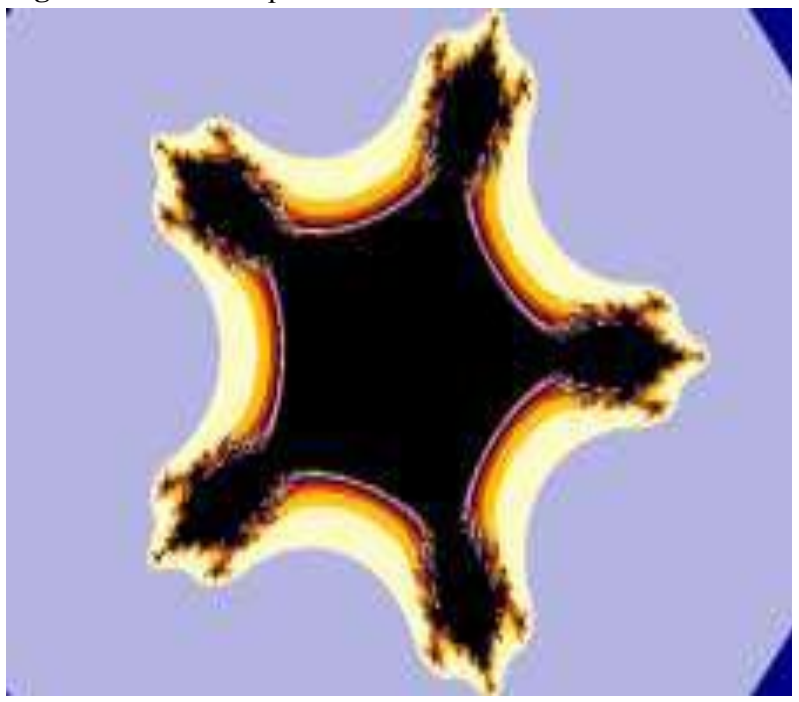

Fig. 18 : Relative Superior Multicorns for $\mathrm{s}=0.8, \mathrm{~s}^{\prime}=0.2$

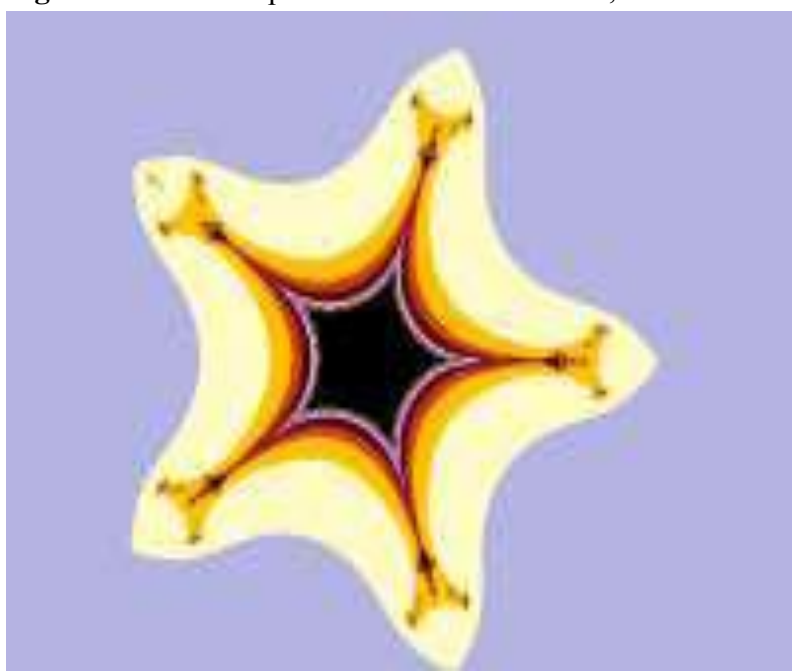

\section{Generalization of Relative Superior Multicorns}

Fig. 19 : Relative Superior Multicorns for $\mathrm{s}=0.1, \mathrm{~s}$ ' $=0.3$, $\mathrm{n}=19$

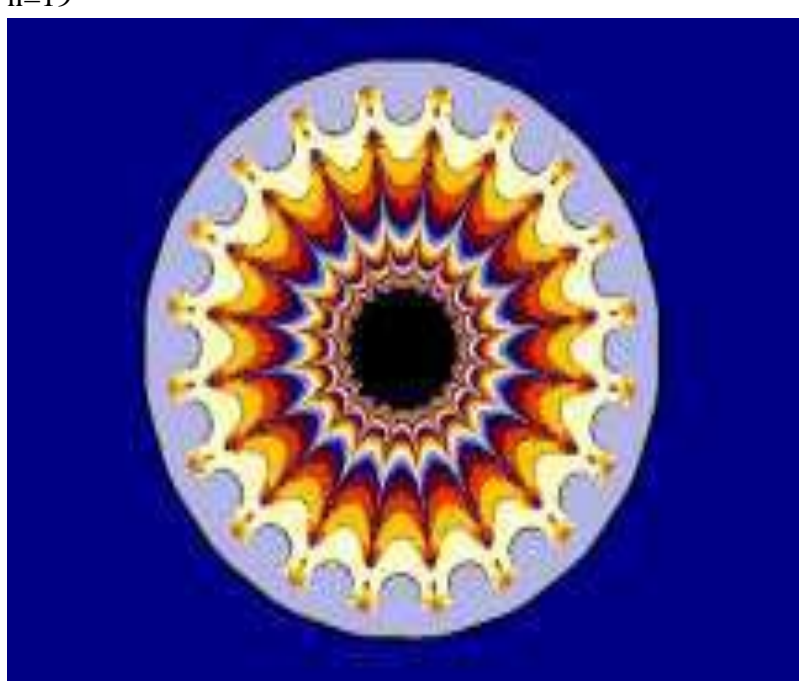

Fig. 20 : Relative Superior Multicorns for $\mathrm{s}=0.1, \mathrm{~s}=0.3, \mathrm{n}=52$

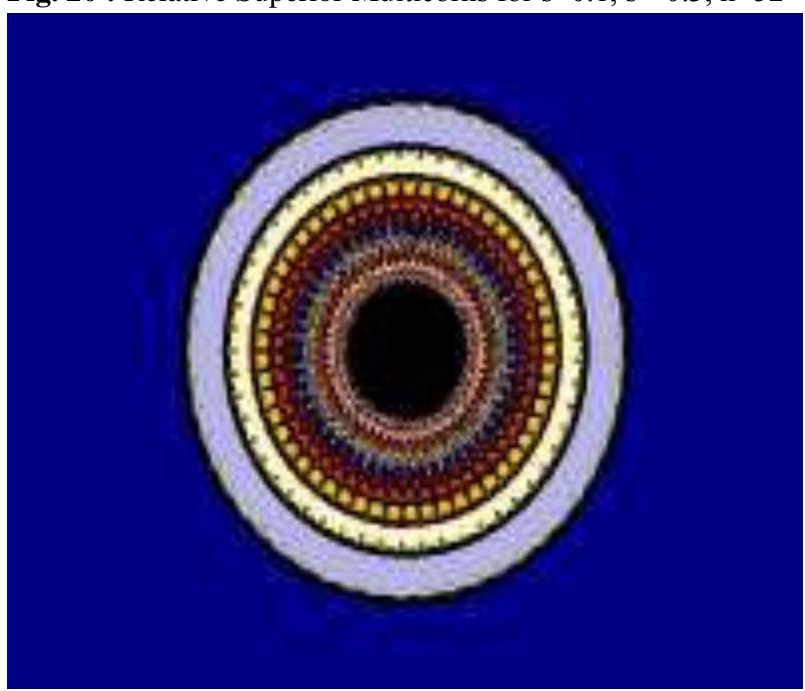

\section{CONCLUSION}

- The geometry of Relative Superior Julia sets and Mandelbrot set are explored for Ishikawa iteration and corresponding fractal images are generated. Different types of orbit traps are generated for Ishikawa iteration procedure.

- The study shows that these sets are exclusively elite and effectively different from other existing Mandelbrot sets. In dynamics of antipolonomial of complex polynomial $\mathrm{z}^{\mathrm{n}}+\mathrm{c}$, where $n \geq 2$, there exist many Tricorns and Multicorns antifractals for a value of $\mathrm{n}$ with respect to Relative Superior orbit.

- Further, for the odd value of n, all the Relative Superior Multicorns are symmetrical objects, and for even values of $n$, all the Relative superior Multicorns (including Relative Superior Tricorns) are symmetrical about $\mathrm{x}$-axis. 


\section{ACKNOWLEDGMENTS}

Our thanks to Dr. A.K Swami, Principal, G.BPant Engineering College, Ghurdauri, for providing necessary infrastructure for the research work. We would also like to thank Mr. Yashwant Singh Chauhan, Assistant Professor, Department of Computer Science and Engineering, G.B.Pant Engineering College, Ghurdauri, for his unconditional and valuable support in writing this paper.

\section{REFERENCES}

[1] R.Abraham and C.Shaw, Dynamics : "The geometry of Behaviour, Part One: Periodic Behaviour, Part Two : Chaotic Behaviour" Aerial Press, Santa Cruz, Calif,(1982)

[2] Alan F.Beardon, "Iteration of Rational Functions", Springer Verlag, N.York, Inc.(1991)

[3] B.Branner and J.Hubbard, "The iteration of Cubic Polynomials". Part I, Acta. Math.66(1998), 143-206

[4] Yashwant S Chauhan, Rajeshri Rana and Ashish Negi, "New Julia Sets of Ishikawa Iterates", International Journal of Computer Applications (0975-8887), Volume 7 - No.13, October 2010

[5] Yashwant S Chauhan, Rajeshri Rana and Ashish Negi, "New Tricorn \& Multicorns of Ishikawa Iterates", International Journal of Computer Applications (09758887), Volume 7 - No.13, October 2010

[6] R.M.Crownover, "Introduction to Fractals Chaos, Mandelbrot sets", Jones and Barlett Publishers, (1995)

[7] R.L.Daveney, "An Introduction to Chaotic Dynamical Systems " Springer-Verlag, N.york. Inc.1994

[8] R.L.Daveney, "A First Course in Chaotic Dynamical System : Theory and Experiment", Addison-Wesley, 1992. MR1202237

[9] S.Ishikawa, "Fixed points by a new iteration method", Proc. Amer. Math. Soc.44(1974), 147-150
[10] Manish Kumar, and Mamta Rani, "A New Approach to Superior Julia Sets”, J.nature. Phys. Sci, 19(2), (2005), $148-155$

[11] Eike Lau and Dierk Schleicher, "Symmetries of fractals revisited.”, Math. Intelligencer (18)(1)(1996), 45-51. MR1381579 Zbl 0847.30018.

[12] B.B.Mandelbrot, "The Fractal aspects of iteration of $z \rightarrow \lambda z(1-z)$ for complex $\lambda$ and z" Ann. N.Y.Acad. Sci. 357(1980), 249-259

[13] W.R.Mann, "Mean Value Methods in iteration", Proc. Amer. Math. Soc.4 (1953), 506-510

[14] J.Milnor, "Dynamics in one complex variable; Introductory Lectures", Vieweg(1999)

[15] Shizuo Nakane, and Dierk Schleicher, "Non-local connectivity of the Tricorn and multicorns", Dynamical Systems and chaos (1)(Hachioji, 1994), 200-203, World Sci. Publ., River Edge, NJ, 1995 MR1479931.

[16] Ashish Negi, "Generation of Fractals and Applications", Thesis, Gurukul Kangari Vishwvidyalaya, (2005)

[17] Ashish Negi, Shashank Lingwal and Yashwant Singh Chauhan, "Complex and Inverse Complex Dynamics of Fractals using Ishikawa Iteration", International Journal of Computer Applications (0975-8887) Volume 40No.12, February 2012

[18] M.Rani and V.kumar, "Superior Mandelbrot Set", J Korea Soc. Math. Edu. Series, DResearch in Maths. Edu. No.4,8(2004), 279-291

[19] K.Shirriff, "Fractals from Simple Polynomial Composite Functions", Computer and Graphics, 17(6), Nov. 1993, pp 701-703

[20] R.Winters, "Bifurcation in families of Antiholomorphic and biquadratic maps", Thesis, Boston Univ. (1990). 